\title{
A territorialização do desenvolvimento: construindo uma proposta metodológica
}

The territorial development: building a methodological proposal

\section{La territorialisation du développement: construire une proposition méthodologique}

\author{
La territorialización del desarollo: la construcción de una propuesta metodológica
}

\author{
Lucas Labigalini Fuini* \\ (lucasfuini@ourinhos.unesp.br)
}

Recebido em 30/11/2012; revisado e aprovado em 23/01/2013; aceito em 16/02/2013

\begin{abstract}
Resumo: O presente texto tem por objetivo construir um conjunto metodológico para estudos envolvendo os aspectos territoriais do desenvolvimento, a partir de dois planos de investigação: o analítico, referente às categorias e modelos de desenvolvimento dentro do repertório da territorialização-desterritorialização-reterritorialização; e o conceitual, referente às concepções de território, desenvolvimento territorial, em seus aspectos qualitativos, escalares e temporais.

Palavras-chave: Violência. Desenvolvimento social. Capital social.

Abstract: This paper aims to build a set for methodological studies involving territorial aspects of development, from two research plan: the analytical, related to development categories and models within the repertoire of territorialization, deterritorialization-reterritorialization, and the conceptual: regarding conceptions of territory, territorial development, in their qualitative, scalar and temporal aspects.

Key words: Development. Territorialization. Deterritorialization.

Resummé: Ce document vise à créer un ensemble méthodologique pour études sur des aspects territoriaux du développement, à partir de deux plan de recherche: l'analyse, se référant aux catégories et modèles de développement dans le répertoire de la territorialisation, déterritorialisation-reterritorialisation; et conceptuelle; se rapporter à conceptions du territoire et le développement territorial, dans leurs aspects qualitatifs, scalaires et temporelles.

Mots-clés: Développement. Territorialisation. Déterritorialisation

Resumen: Este trabajo tiene como objetivo construir un conjunto metodológico para los estudios relacionados con los aspectos territoriales de desarrollo, por dos planos de investigación: el analítico, en referencia a las categorías y modelos de desarrollo dentro del repertorio de territorialización, desterritorialización reterritorialización; y conceptual, con respecto a las concepciones de territorio y el desarrollo territorial, en sus aspectos cualitativos, escalar y temporal.

Palabras clave: Desarrollo. Territorialización. Desterritorialización.
\end{abstract}

\section{Introdução}

O período atual é marcado, segundo Harvey (2009), por uma intensa compressão do espaço-tempo, compressão esta que tem exercido uma influência desorientada e de rompimento sobre as práticas político-econômicas, sobre o equilíbrio do poder de classe, bem como sobre a vida social e cultural. E a principal razão desse processo corrente foi a transição do modelo de acumulação fordista para o de acumulação flexível, que trouxe a rápida implantação de novas formas organizacionais e novas tecnologias produtivas. Assim, pode-se afirmar que se produziu uma compressão do espaço pelo tempo, dada a velocidade dos fluxos transitando por redes materiais de comunicação e informação, delineando o seguinte cenário:
Se os capitalistas se tornam cada vez mais sensíveis às qualidades espacialmente diferenciadas de que compõe a geografia do mundo, é possível que as pessoas e forças que dominam esses espaços os alterem de um modo que os torne mais atraentes para o capital altamente móvel. (HARVEY, 2009, p. 266).

Nesse sentido, um dos fenômenos marcantes a definir essas novas qualidades do espaço e suas especificidades na construção de territórios e lugares foi a crescente integração dos mercados, da produção e das finanças, a denominada globalização, processo que funda uma nova divisão territorial do trabalho que acirra as desigualdades no espaço mundial.

Castells (2003) caracteriza a nova economia emergente no final do século XX como

* Universidade Estadual Paulista (UNESP), Ourinhos, São Paulo, Brasil. 
simultaneamente global, informacional e em rede. E essa característica global decorre do fato de que as principais atividades produtivas, o consumo, a circulação, assim como seus desígnios (capital, trabalho, matérias-primas, informação, tecnologia e mercados) estão organizados em escala global, mediante redes de conexões envolvendo agentes econômicos cujo diferencial competitivo, tanto no âmbito das empresas, quanto no das regiões e nações, depende basicamente de sua capacidade de gerar, processar e aplicar de forma eficiente a informação baseada em conhecimentos.

Em contrapartida, a globalização é um processo inerentemente capitalista e de viés econômico e que traz um caráter desterritorializador, tanto nos discursos quanto nas práticas. Segundo Haesbaert; Porto-Gonçalves (2006), a globalização econômica estendida em todo o planeta teria como pré-requisitos a ruptura de fronteiras, a perda de influência de condicionamentos locais e expansão de uma dinâmica de acumulação e a concentração de capital no mundo. No entanto essa desterritorialização é mais um argumento de defesa da integração econômica mediante a desregulamentação dos mecanismos de trocas e de produção, do que efetivamente a realidade de um planeta com Estados-nação enfraquecidos e destituído de fronteiras econômicas, sociais e políticas. O que ocorre na verdade é o advento de uma nova ordem mundial e divisão internacional do trabalho que passa a diferenciar os espaços produtivos conforme seu nível tecnológico e qualificação/custos da força-de-trabalho, aprofundando as desigualdades e diferenciações entre regiões e lugares.

O elemento espacial e estrutural de entendimento da globalização, a face geográfica desta, é o meio técnico-científico-informacional (SANTOS, 1996). O conteúdo espacial e temporal do MTCI se baseia na interação da ciência com a técnica na obtenção de funcionalidades que facilitem a atuação do mercado globalizado, sendo que os objetos geográficos criados precisam gerar informações sobre todos os aspectos do mundo, inclusive sobre a natureza. No Brasil, a expansão dos recursos da informação ocorre de forma seletiva e abre novas possibilidades da produção e circulação dos insumos, produtos, dinheiro, ideias, informações, ordens e homens. Essa fluidez do espaço passa a distinguir áreas mais ou menos valorizadas conforme a influência das informações e das finanças, definindo novos usos e zonas de densidade e zonas de escassez de capital e infraestrutura.

Assim, muda-se a característica territorial do desenvolvimento capitalista em suas diferentes escalas espaciais. O desenvolvimento, como um processo histórico combinado de incremento da renda agregada, da produtividade econômica e dos padrões de vida vai se concretizar e se diferenciar nos níveis locais e regionais de análise. A territorialização do desenvolvimento envolve a consideração de duas linhas de análise importantes (DALLABRIDA et al., 2004).

A primeira, a globalista, trata as regiões e lugares como espaços homogêneos face à difusão das redes econômicas de integração produtiva, comercial, financeira e tecnológica no âmbito mundial. É parte da proposta da relação dialética entre o global e o local, relação esta responsável pela nova divisão do trabalho e pelos conflitos entre mundialização do capital, poder do Estado e características regionais.

A segunda, a regionalista, que associa o desenvolvimento às potencialidades, recursos e arranjos institucionais criados em locais e regiões específicos. Apesar de difusa, essa corrente reconhece a importância das relações horizontais relativas à produção local e as relações de solidariedade produtiva entre agentes e cidades que compõem uma região (SANTOS, 1996). Em contraponto à crise do fordismo e do Estado keynesiano, pautados na rigidez e padronização, os regionalistas buscam compreender as vantagens da diferenciação entre localidades em termos de inovação em arranjos de empresas e pactos políticos e sociais para resolver os problemas do crescimento da renda e do emprego. Pecqueur (2009) chega a tratar dos ganhos competitivos associados à qualidade e especificação da produção em estratégias de ancoragem territorial coordenadas por instituições locais, como nos casos das certificações de origem e denominação controladas.

Podemos afirmar, portanto, que a análise do desenvolvimento no período técnicocientífico-informacional da globalização é cada vez mais marcada pela realidade de um processo contínuo de territorialização, desterritorialização e reterritorialização das 
estratégias e dinâmicas socioeconômicas e políticas que criam e sustentam o desenvolvimento. Territorialização indica, enquanto conceito explicativo bastante difundido por Haesbart (2004), o enraizamento e identificação de um grupo, organização ou indivíduo com um território, tanto em termos políticos, econômicos, mais materiais, quanto em termos culturais e simbólicos, fortemente imateriais.

No entanto, com a deslocalização crescente dos capitais e a velocidade crescente dos fluxos em redes, aumenta em intensidade o movimento de desterritorializar, seja por se perder laços de vinculação, identificação e apropriação relacionados a um território em específico, pelo próprio desejo de deslocalizar ou por necessidade conduzida pela exclusão e segregação socioespacial.

Em termos econômicos, podemos tanto falar da desterritorialização planejada das empresas transnacionais quanto da desterritorialização não planejada e caótica das pequenas empresas e negócios locais, subordinados à lógica oligopolista de concentração capitalista e que faz com que ora desapareçam e ora reapareçam. Assim, a reterritorialização é esse movimento de busca por reconstruir vínculos de inserção e reestruturação em outros espaços que não os de origem, ou em momentos históricos diferentes com outras funções e formas. No desenvolvimento, a reterritorialização é sintoma de mobilidade funcional de uma empresa ou como estratégia de resistência ou sobrevivência de um produto e marca no cenário competitivo globalitário (SANTOS, 2001).

Desse modo, o presente artigo busca considerar os principais elementos constituintes do período e processo de globalização e de seu arcabouço geográfico do meio técnicocientífico informacional, para então avaliar as estratégias de T-D-R relacionadas ao movimento contemporâneo das ações públicas e privadas para o desenvolvimento.

A hipótese de estudo é que as reações locais e regionais pró-desenvolvimento podem indicar não somente a territorialização dos recursos de capital e de conhecimento, mas também a desterritorialização como forma de competição pensada na apropriação crescente de renda das cadeias globais de valor. Nesse sentido, a territorialização do desenvolvimento não indica necessariamente uma única forma de apropriação e dominação de um processo em um lugar específico, mas sim a apropriação e cruzamento de redes relacionais em múltiplos lugares, a multiterritorialização. Posto assim, o desenvolvimento regional/local atual é muito mais uma questão de multiterritorialização, necessária como estratégia competitiva, do que de singularidade geográfica de corte uniterritorialista.

Partindo dessas premissas, propomos um modelo de análise da territorialização do desenvolvimento que passa por dois níveis de entendimento: um primeiro nível, analítico e metodológico, que busca entender os movimentos contemporâneos de desterritorialização e territorialização pelo prisma das redes e dos aglomerados, conduzindo a discussão para o campo da teoria do desenvolvimento e dos sistemas produtivos territorializados; e um segundo nível, conceitual e processual, que traz a reflexão sobre a territorialização do desenvolvimento em diferentes perspectivas, colocando seus elementos principais em termos de conteúdos, escalas espaciais e ciclos de tempo.

\section{O primeiro nível - analítico: $O$ movimento T-D-R e suas configurações espaciais}

A territorialização e desterritorialização dos atores sociais passam necessariamente pela influência dos elementos da globalização e dos fluxos técnico-científico-informacionais. As configurações espaciais possíveis para esses movimentos envolvem a configuração de redes, os aglomerados e os sistemas.

As redes são definidas pela conexão e ligação que está na base de fluxos de mercadorias e de informações. Segundo Dias (2006), os nós das redes são lugares de conexão, lugares de poder e de referência, solidarizando os elementos espaciais. Os fluxos de informação, na atualidade, são decisivos na constituição de movimentos materiais e imateriais e na articulação de objetos e ações em rede. Castells (2006) afirma que a nova economia da globalização tem no funcionamento em rede um de seus aspectos centrais, pois as tecnologias das informações e comunicação deram a possibilidade de ocorrer uma conexão histórica entre a base de conhecimentos e informações 
de alcance global, criando um novo sistema econômico pautado na produtividade das redes de conexões entre agentes econômicos.

Santos (1996) compreende que as redes são infraestruturas com fluidez de comunicação e inter-relações sociais, não sendo mais apenas territoriais, pois envolvem a participação de objetos técnicos, como computadores e telecomunicação. As redes são responsáveis hoje pela divisão do trabalho e operam de maneira dialética, por dois motivos:

a) Estabelecem a relação entre os territórios nos níveis mundial, nacional e local, conectando a sociedade local que executa o trabalho propriamente dito com o território nacional que realiza o trabalho político, com suas leis, incentivos e planos, e o global, que demanda trabalho e realiza investimentos produtivos ou especulativos;

b) A necessidade de fluidez sócio-técnica através da intensificação da circulação interagindo com as novas formas de organização que geram simultaneamente, em perspectiva geográfica, ordem e desordem, organização e desorganização.

Na escala global e nacional, a redes organizam o espaço de atuação das grandes corporações, buscando reduzir o tempo de circulação entre escalas; já em escala local, as redes geram desordem, pois buscam a desregulamentação e o ajuste das leis locais aos organismos internacionais, criando problemas de exclusão social e marginalização vistos, de forma mais densa, em centros e aglomerados urbanos.

No entanto, apesar da crença generalizada no fim dos territórios e regiões devido à homogeneização e indiferenciação espacial, ocorre o contrário, a comunicação através de novas redes se pauta na seletividade espacial e na importância estratégia da localização geográfica (DIAS, 2006). O que está a ocorrer atualmente, e em virtude da organização espacial em rede, é a sucessão cada vez mais rápida de movimentos de territorialização, desterritorialização e de reterritorialização, tanto do capital em movimento quanto das sociedades locais e regionais.

Haesbaert (2006) enfatiza que a produção do espaço envolve, concomitantemente, a desterritorialização e a reterritorialização. $\mathrm{O}$ sentido de desterritorialização está atrelado tanto à superação de barreiras de distâncias físicas quanto à mobilidade da sociedade e das finanças, e essa superação tem como elementos de condução as redes de transportes e de informações e comunicações. Por outro lado, traz também o sentido de desenraizamento pela perda de fronteiras políticas e destruição de referenciais de apropriação simbólico-culturais. Desterritorializar indica perder a conexão entre territórios no sentido político e cultural, processo este provocado por elementos e processos de cunho econômico e político.

Entendemos que a desterritorialização significa menos o desaparecimento de territórios e mais a mobilidade entre territórios, a capacidade atual que as tecnologias de difusão de informações e comunicações dão ao capitalismo para estar localizado em vários lugares e neles buscar formas de fixação nos âmbitos local e regional, ao mesmo tempo que também requer mobilidade e poucas amarras fronteiriças para operar nos âmbitos nacional e global. Trata-se, então, mais de uma multiterritorialização do que de uma desterritorialização.

Portanto a reterritorialização tem o sentido de reconstrução dos aspectos políticos e culturais definidores das dimensões sociais fundamentais do território, dimensões que envolvem as relações e sentimentos de identidade, enraizamento e controle. Assim, ressurgem os limites, as fronteiras e as relações horizontais de produção local entre cidades, meios rurais e pessoas. Os efeitos perversos da territorialização contemplam práticas sociais e espaciais segregacionistas, o conservadorismo político, social e cultural e o fechamento dos territórios ao seu entorno exterior.

A rede, portanto, seria uma marca de desterritorialização ou daquilo que faz a mediação entre a organização e desorganização, destruição e reconstrução, a ordem e a desordem. As redes geralmente estão muito associadas aos circuitos de fluidez do capital internacional, portanto seriam logo associadas à desterritorialização. No entanto se envolvem também em outras escalas e tempos passados ou futuros em uma perspectiva reterritorializante. Coloca-se, portanto, a necessidade de se diferenciar, segundo Randolph (1993; 1999, apud HAESBAERT, 2006), as redes estratégicas técnico-funcionais - de lógica de ação global e mais desterritorializadas - das 
redes sociais de solidariedade, com caráter reterritorializador e mais ligadas à lógica de ação local.

Atuam sobre os territórios locais, simultaneamente, um tipo de ação vertical, baseada na modernização e distribuição de produtos e créditos para os lugares através de redes articuladas pelo grande capital, pautadas em uma solidariedade organizacional. E opera também uma lógica de ação horizontal, a partir de ações localmente constituídas, permitindo a ampliação da coesão da sociedade civil a serviço do interesse coletivo, construindo um cotidiano homólogo consubstanciado em uma solidariedade ativa e maior eficácia política (SANTOS, 1996; HAESBAERT, 2004).

As redes se colocam como intermediárias entre um conjunto de aglomerados desterritorializados, desenraizados, desqualificados e deslocados, para um conjunto territorial enraizado e qualificado associado às ideias de comunidade, nação e identidades regionais. A dialética relacional e conflituosa entre mobilidade técnica e a coesão social e simbólica dá à rede o caráter de elemento que vai configurar (unificar) ou desestruturar territórios.

A concepção de aglomerado nos traz a perspectiva de uma massa disfuncional sem identidade e espacialmente definida por um ponto, linha ou superfície. Haeasbaert (2004, 2006) quando realizou sua fundamental reflexão sobre a desterritorialização do capital e dos povos e cunhou a relação entre redes e aglomerados, focou sua análise nos conjuntos populacionais em situações de exclusão social e marginalização econômica. Não propôs o uso do modelo de T-D-R para a análise do conjunto de estabelecimentos de produção e serviços e de sua lógica de aglomeração e deslocalização.

Ao sistematizar uma tipologia para aglomerados, aparecem três tipos centrais: aglomerados radicais, marcados pelas condições de vida precárias e extremas, como os refugiados e deslocados em áreas de países pobres; aglomerados tradicionais, vivendo em situações endêmicas de exclusão e fome (Ex.: Sertão nordestino brasileiro); e os aglomerados transitórios ou conjunturais, geralmente de caráter ilegal ou clandestino e marcados pela violência e medo (Ex.: Favelas dominadas pelo narcotráfico).

E no avançar do século XXI, em vigor ainda o capitalismo globalizado, não seria possível pensar em movimentos de T-D-R para aglomerados produtivos, pensados em termos de configuração espacial/regional e política, tal como os Clusters, Distritos industriais marshallianos, Meios inovadores, Arranjos e Sistemas Produtivos Locais (APL/ SPLs)?

Benko (1996) coloca, no debate sobre a geografia dos novos espaços econômicos, a importância da constituição de redes associadas à política. A rede é definida como uma forma de organização interempresarial que vai além de relações de mercado e que envolve a governança, ou seja, as relações de hierarquia, cooperação e parceria entre atores públicos, privados e a sociedade civil. Portanto, no caminhar de um modelo de acumulação flexível (HARVEY, 2009), as redes adquirem um caráter funcional e simbólico de gerir as unidades econômicas e sua cooperação, através das redes de transportes e comunicações. Assim, poderia se falar de distritos que se comportam como redes (distritos em rede), redes estas ao mesmo tempo sociais e técnicas e mais territorializadas; e redes de distritos em escala nacional e internacional, com caráter mais deslocalizado e desterritorializado.

A governança, entendida como a regulação das relações de poder e de coordenação, no contexto de distritos e aglomerados produtivos (clusters), serve para criar nesses ambientes produtivos elementos de reterritorialização que eles ainda não têm ou que perderam. No âmbito estritamente mercantil e técnico, as redes de subcontratação e de fornecimento pensadas isoladamente podem atuar no sentido de desterritorializar o distrito ou o cluster, tornando-o um simples nexo de cadeias produtivas globalizadas ou caminhando para a desconcentração de investimentos em busca de lugares de produção mais baratos que aqueles de origem.

Em análise paradigmática, Lipietz; Leborgne (1988) definem três grandes modelos de desenvolvimento territorializado que se diferenciam por envolverem diferentes formas de organização do paradigma tecnológico, da produção industrial (maior ou menor nível de desintegração vertical e territorial das firmas) e formas de gerenciamento das relações de trabalho. Nesse sentido, mais próximo de um modelo desterritorializado, teríamos as áreas produtivas especializadas, 
e, na sucessão de modelos mais territorializados, aparecem os sistemas produtivos locais e as áreas-sistemas.

As áreas produtivas especializadas são aglomerações de formação recente, que estabelecem pouca relação com a formação social preexistente. São monossetoriais, orientadas para a exportação e com fracas relações interfirmas no território, com contratos de trabalho de tipo flexível e com pequeno engajamento dos trabalhadores. Seria mais próximo daquilo que podemos definir como simples aglomerados de atividades econômicas especializadas. Os sistemas produtivos locais, também são monossetoriais e orientados pela demanda exterior, mas apresentam uma especialização intrassetorial das firmas e tendência à cooperação e quase integração vertical entre as firmas no local (redes de relacionamentos e interdependência). Apresentam uma oferta local de qualificação profissional, e as firmas podem ser de origem interna ou externa à região. Trata-se de um caso que apresenta maior nível de territorialização devido à coordenação entre firmas estabelecidas nos lugares onde operam e à dependência de serviços e outras amenidades e externalidades do meio regional, como a tradição e o saber-fazer, sendo possível classificar, nesse conjunto, os arranjos produtivos locais existentes no Brasil, meios inovadores, sistemas locais de inovação e os tecnopolos.

Por fim, temos o modelo deáreas-sistemas, modelo quase utópico de desenvolvimento que apresenta engajamento dos trabalhadores, negociações coletivas entre sindicatos e uniões patronais, relações profissionais baseadas na cooperação e qualificação, em redes integradas territorialmente, multissetoriais e diversificadas, com empresas especializadas e contratantes. Conta ainda com um consenso social necessário para a difusão organizada e planejada do saber local, com elos estreitos entre os sistemas bancário e industrial regional, apresentando ainda ampla possibilidade de promoção social através de educação e engajamento. Esse formato se aproxima mais das teorizações sobre distritos industriais da Terceira Itália, com a presença de uma atmos- fera industrial marshalliana e de uma comunidade formada por empresas, trabalhadores e governo regionais em cooperação.

Esse terceiro modelo de áreas-sistemas, por estar muito longe da realidade brasileira, pautada espacialmente pelos conflitos e a exclusão socioeconômica, dará espaço a uma lógica de reflexão do movimento de T-D-R das aglomerações econômicas através dos exemplos das aglomerados industriais, das áreas produtivas especializadas e dos sistemas produtivos locais. E esses aglomerados industriais podem ser definidos como agrupamentos de estabelecimentos de produção e de serviços de distribuição e comercialização que se aproximam geograficamente por vantagens locacionais do ponto de vista técnico (Ex.: proximidade de rodovias e ferrovias, do mercados consumidores, baixos custos de produção) ou organizacional (Ex.: Incentivos fiscais, legislações brandas, regulamentação flexível do trabalho), envolvendo vários segmentos de atividades e com poucas relações entre as firmas.

Assim, entendemos que existe uma mobilidade entre modelos de desenvolvimento segundo seu nível de territorialização, e esse nível de territorialização transita entre a desterritorialização, a reterritorialização e a multiterritorialização. É possível também afirmar que, em dado modelo de desenvolvimento, coexistem partes mais territorializadas e partes desterritorializadas de seu aparato socioprodutivo, e essas características híbridas estão associadas às estratégias competitivas e formas de governança utilizadas pelo conjunto de atores a operar nas diferentes escalas espaciais. E pela própria tendência de economias de aglomerações constituídas regionalmente passarem por um crescimento e amadurecimento é que podemos afirmar que modelos de desenvolvimento inicialmente desterritorializados se tornam, à medida que reforçam os vínculos de interdependência internos e consolidam seus mercados externos, cada vez mais multiterritorializados, com envolvimento em redes e cadeias produtivas e de comercialização nacionais e globais. 
Tabela 1 - Modelos de desenvolvimento e o nível de territorialização

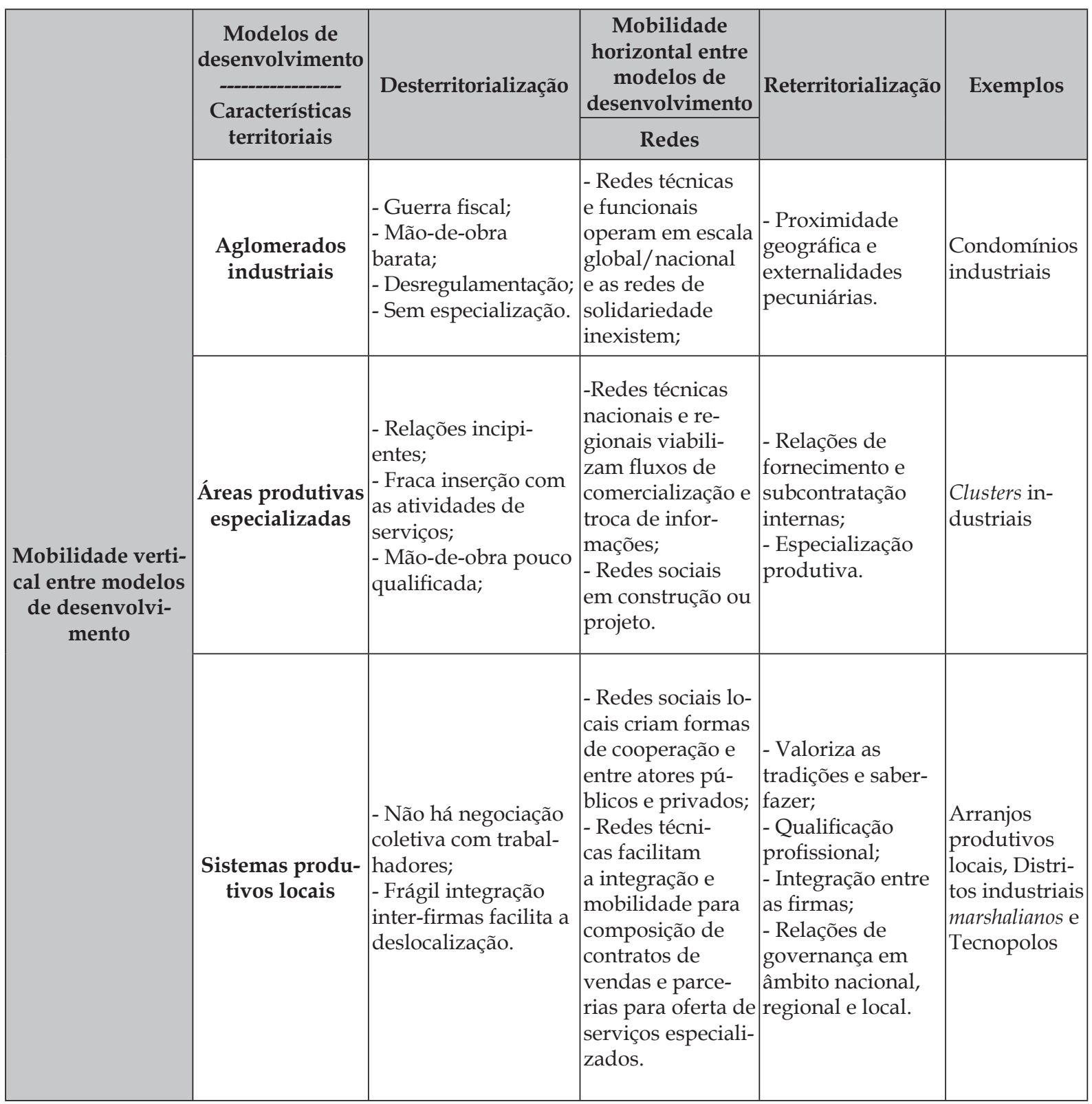

Fonte: Elaborado pelo autor

\section{O segundo nível - conceitual: território e desenvolvimento territorial}

Segundo o geógrafo Roberto Lobato Corrêa, em prefácio para a obra de Haesbaert (2004), o território é um conceito derivado do espaço geográfico e é um produto da apropriação de um dado segmento do espaço por um grupo social que nele estabelece relações políticas e de controle ou relações afetivas, identitárias e de pertencimento. E complementa

O mundo moderno é recoberto por inúmeros territórios, justapostos ou parcial ou totalmente recobertos entre si, contínuos ou descontínuos, permanentes ou temporários. Esta pluralidade de território aponta para a sua força como componente essencial da vida social.

Envolto de forma permanente em relações de ordem material e funcional e de ordem imaterial e simbólica, o território permite, para sua análise, a definição dos seguintes conteúdos ou vertentes básicas de entendimento (HAESBAERT, 1997; 2004; 2006; HAESBAERT; LIMONAD, 1999): a) Política: refere-se às relações espaço-poder em geral ou jurídico- 
políticas, sendo que o território é visto como um espaço controlado e delimitado por um determinado poder, geralmente relacionado ao poder político do Estado; b) Econômica: enfatiza a dimensão espacial das relações econômicas, sendo que o território pode ser visto sob três prismas: como fonte de recursos; incorporado no embate entre classes sociais ou como produto da divisão territorial do trabalho fruto da relação capital-trabalho; c) $\underline{\text { Cultural: prioriza a }}$ dimensão simbólica e subjetiva, sendo visto o território como produto da apropriação/ valorização simbólica de um grupo em relação ao seu espaço vivido; d) Natural: é a base das relações entre sociedade e natureza, especialmente no que se refere ao comportamento dos homens em relação ao seu ambiente físico e o a noção de "equilíbrio" entre os grupos sociais e animais e os recursos do meio.

Spósito (2004) analisa que as mudanças correntes no mundo atual colocam à compreensão do território duas problemáticas fundamentais: a) o desenvolvimento tecnológico e as redes de informação rompem com as barreiras de distância e fazem os territórios perderem fronteiras, mudando de tamanho e da configuração geográfica, com aumento de lutas por necessidades territoriais nacionais e minorias contra a homogeneização capitalista; b) Consideração do indivíduo e da escala do cotidiano, como formas de apreensão das dimensões territoriais e da capacidade de exercício da liberdade pela satisfação das necessidades individuais, envolvendo elementos de projeção como a solidariedade e a inventividade.

Santos (1996) complementa expressando que o território é um elemento intermediário entre o mundo e a sociedade nacional e local, pois a globalização só se realiza em lugares, conforme sua virtualidades e recursos para usos específicos. E esse mundo globalizado escolhe determinado lugares e rejeita outros para sua territorialização, não abarcando o espaço como um todo e deixando o território como algo fragmentado.

Conforme o quadro conceitual apresentado anteriormente (Tabela 1), podemos entender que as afirmações sobre a territorialização do desenvolvimento e o desenvolvimento dos territórios envolvem diferentes perspectivas de entendimento sobre as qualidades do território e as estratégias de desenvolvimento. Mas é possível afirmar que o território, por ser o espaço utilizado, apropriado, controlado, delimitado e organizado, por si só já envolve relações de poder tais que definem determinadas opções de desenvolvimento. Cabe, então, aos investigadores buscar pelo fio analítico da perspectiva histórica, do tempo, e geográfica, do contexto espacial, entender tais opções de desenvolvimento e se estas modificaram as condições de organização territoriais pré-existentes, rumando ou para a desterritorialização de atores e redes ou para a multiterritorialização como estratégias de expansão. Daí a importância, nesse fio analítico, de se consultar as bases políticas, econômicas, culturais e ambientais para se entender o desenvolvimento territorial.

No Brasil, a tradição de pensamento sobre a territorialização do desenvolvimento pode ser remetida ao economista Celso Furtado, com sua teoria sobre o subdesenvolvimento brasileiro (FURTADO, 2003) e sua ação para diminuição da histórica concentração de renda entre regiões com o projeto da Sudene (Superintendência de Desenvolvimento do no Nordeste). Em escala territorial nacional e internacional, Furtado pensavam no dualismo centro-periferia do capitalismo como causa primaz de nosso atraso tecnológico, afirmando que o desenvolvimento dos países centrais tinha como contrapartida o subdesenvolvimento dos países periféricos na divisão internacional do trabalho.

Nessa mesma linha interpretativa, acreditava que apenas reformas estruturais que modificassem o acesso aos recursos do capital poderiam modificar o quadro de desigualdades brasileiro e, assim pensando no âmbito regional, refletia que a territorialização do desenvolvimento subnacional dependia da ação do Estado como indutor de investimentos, promovendo transferência tecnológica, qualificação da força-de-trabalho e rompimento com formas arcaicas de poder político que se faziam refletir nos processos de produção e no ambiente de formação cultural e social.

Nesse horizonte de ideias que circularam desde então, pois as primeiras contribuições de Furtado datam dos anos 1930, uma grande quantidade de propostas teóricas, conceituais e empíricas vicejaram desde os anos 1980 em razão da retomada do pensamento sobre o desenvolvimento em escala regional e local, mormente interpretadas pelo viés da 
acumulação flexível e da crise do Estado, que exigiriam respostas em âmbito local e regional para os problemas do desenvolvimento. Mais recente ainda, de finais de 1990 em diante, outras propostas consideraram a validade dos aportes keynesianos sobre o desenvolvimento em escala nacional e regional e as atualizaram para o debate sobre uma política de desenvolvimento regional que conciliasse a retomada da capacidade de investimento do Estado em seus quadros subnacionais com a valorização do capital social, das governanças e dos recursos econômicos e culturais mobilizados em territorialidades locais.

Assim, Boisier (2000) retoma esse debate colocando um questionamento para o período atual: "desenvolvimento: de que estamos falando?". Assim, o autor assume a importância do conceito, uma utopia social, mas reconhece que, em tempos recentes, ocorreu uma proliferação de adjetivos para ele (territorial, regional, local, endógeno, sustentável, humano, desde baixo), que em muitos casos criou mais redundância que esclarecimento, refletindo o cenário de especialização funcional de instituições acadêmicas e políticas.

$\mathrm{Na}$ apreensão espacial sobre o desenvolvimento, Boisier (2000) define o desenvolvimento territorial como um continente, ou contexto, e não um conteúdo para a discussão. O desenvolvimento territorial seria a escala geográfica de um processo, e não seu conteúdo, podendo ser analisado em diversos cortes ou níveis: mundo, continente, país, região, Estado, província, departamento, comunas, corregedorias ou municipalidades.

Além disso, a discussão sobre o desenvolvimento territorial atenderia a um nível de complexidade crescente, que evoluiria do território natural (recorte primário definido pelos elementos da natureza, com poucas intervenções humanas), para o território equipado (no qual o homem instalou sistemas de transportes, obras de infraestrutura e algumas atividades produtivas extrativas), e deste para o território organizado (marcado pela existência de atividades de maior complexidade, de sistemas assentamentos humanos, redes de transporte e a pela presença de uma comunidade que se reconhece no território é regulada por um dispositivo político-administrativo, com ordenamento jurídico nacional e estruturas de administra- ção e governo). Nessa leitura, quanto mais organizado for o território, maior será seu nível de desenvolvimento, considerando o prisma da modernização tecnológica e social.

Pires (2007), a partir de ampla revisão bibliográfica, segue um percurso investigativo que se debruça sobre as lógicas territoriais do desenvolvimento, desenvolvimento este que estaria fundado na dependência da sociedade na organização da produção social local ou regional e na criação de instituições com diretrizes locais para organizar expectativas em prol de uma meta comum local-nacional, com o apoio do Estado e das parcerias com as estratégias empresariais privadas.

A primeira delas seria a lógica das escalas (pensando no papel dos territórios locais e na sua relação com a descentralização do Estado, a polarização industrial e a divisão internacional do trabalho), a segunda lógica é a do ator-coletivo (pensado tanto no indivíduo empresário-empreendedor e nas formas de governança públicas) e a terceira lógica, a das ações (pensando no desenvolvimento como processo e em três ações estratégicas: inovação, adaptação e regulação)

Também em grande levantamento teórico-bibliográfico, Dallabrida et al. (2004) buscam definir eixos de análise na perspectiva da territorialização do desenvolvimento. No conjunto dos debates, reconhecem que atualmente é possível pensar no desenvolvimento em perspectiva territorial, pois, diversos estudos identificaram que cidades e regiões não são apenas suportes passivos de localização das atividades econômicas, mas podem se transformar em âmbitos espaciais ativos ao exercerem o protagonismo na decisão sobre seus projetos, sendo que alguns sistemas territoriais de produção são capazes de se desenvolver sem a dependência do crescimento econômico de regiões mais urbanizadas e industrializadas.

Assim, os autores só julgam possível pensar em políticas territoriais de desenvolvimento se: a) houver o redimensionamento do papel do Estado nacional e das capacidades estatais e; b) se esse desenvolvimento se pautar em inovação territorial resultante de aprendizagens coletivas. No entanto coloca o desafio de pensar em desenvolvimento territorial regional em local em um cenário de elevação ou manutenção das assimetrias regionais e um aumento da hegemonia das empresas transnacionais. 
De forma a complementar o presente mosaico dos aspectos territoriais do desenvolvimento, Santos (1996) enfatiza essa discussão do ponto de vista de uma relação dialética entre a ação globalizada como norma, e o território local como norma. A ordem global é desterritorializada, pois separa o centro da ação da sede da ação, impondo uma racionalidade e uma espacialização aos lugares na forma de normas, com seus vetores técnicos, informacionais, econômicos, sociais, políticas e culturais. A ordem local é que reterritorializa, pois reúne em uma lógica interna os homens, empresas, instituições, formas jurídicas e sociais e formas geográficas, no contexto imediato do cotidiano localmente vivido e da comunicação propiciada. Assim se define o território local como uma norma. O território atua, então, como uma mediação entre o mundo e as sociedades nacionais e locais, sendo que o mundo oferece as possibilidades para o desenvolvimento dos territórios e os lugares oferecem as oportunidades.

Esse dado é, hoje, fundamental, já que o imperativo da competitividade exige que os lugares da ação sejam global e previamente escolhidos entre aqueles capazes de atribuir a uma dada produção uma produtividade maior. Nesse sentido, o exercício deste ou daquela ação passa a depender da existência, neste ou naquele lugar, das condições locais que garantam eficácia aos processos. (SANTOS, 1996, p. 271).
Considerando o conjunto teórico do apresentado, sugerimos abaixo alguns quadros qualitativos analíticos para pensar sobre o desenvolvimento na perspectiva da territorialização. Em primeiro momento, faz-se necessário reconhecer os principais conteúdos ou eixos de análise do desenvolvimento territorial, especificando seus temas e assuntos inerentes. Definimos quatro campos fundamentais (separados para critério de análise) pelos quais trilham as propostas e processos de desenvolvimento nas escalas territoriais (Tabela 2).

O campo político, regulatório e de intervenção, relacionado ao Estado e suas instâncias de governo e a dicotomia inerente à ação pública: estimular o crescimento econômico e promover justiça social. O campo econômico, definido pelas aglomerações de atividades econômicas, o quadro institucional de sua ação e a força-de-trabalho organizada ou não presente nos territórios. O campo cultural, das práticas, tradições direta ou indiretamente vinculadas às ações da produção local, que possuem importância vital no desenvolvimento, em perspectiva imaterial, em virtude dos conhecimentos tácitos e convenções construídas coletivamente. O campo ambiental envolve a discussão da responsabilidade socioambiental existente ou não nas territorializações do desenvolvimento, com a perspectiva da resolução conjunta de problemas associados à poluição dos recursos naturais, devastação, pobreza, problemas de nutrição etc.

Tabela 2 - Eixos de análise da territorialização do desenvolvimento

\begin{tabular}{|c|l|}
\hline Eixos de análise & \multicolumn{1}{c|}{ Territorialização do desenvolvimento } \\
\hline Econômico & $\begin{array}{l}\text { Envolve o conjunto das atividades produtivas, infraestruturas de circulação, ca- } \\
\text { deias de serviços e comércio, mercado de trabalho e as instituições representati- } \\
\text { vas do empresariado e dos trabalhadores. }\end{array}$ \\
\hline Político & $\begin{array}{l}\text { Se refere às instâncias de governo locais, regionais e nacionais e as normas e } \\
\text { regras jurídicas do planejamento que atuam no sentido de viabilizar as infrae- } \\
\text { struturas, regulamentar as ações privadas e distribuir os incrementos de renda } \\
\text { entre a população. }\end{array}$ \\
\hline Cultural & $\begin{array}{l}\text { Aglutina o conjunto de tradições históricas atreladas às atividades produtivas, o } \\
\text { saber-fazer local, os pactos e convenções firmados, eventos mais significativos, } \\
\text { atmosfera industrial, cultura de cooperação ou individualismo. }\end{array}$ \\
\hline Ambiental & $\begin{array}{l}\text { Diz respeito ao recorte físico de análise, que pode ser visto como recurso natu- } \\
\text { ral, e aos impactos socioambientais produzidos pelos aglomerados e redes de } \\
\text { produção localizados, ao lado dos acordos políticos para mitigação de danos e a } \\
\text { recuperação ambiental inerentes ao paradigma do desenvolvimento e sustenta- } \\
\text { bilidade ambiental. }\end{array}$ \\
\hline
\end{tabular}

Fonte: Elaborado pelo próprio autor. 
A coerência explicativa para dar sentido à combinação dos eixos de análises do desenvolvimento territorial em determinado tempo e espaço pode ser dada pelo conceito de formação socioespacial, pois, nesse sentido, ela define o uso do território e seu papel de intermediação entre o mundo e a região/lugar. A formação socioespacial supõe a existência, em dado território, de formas geográficas, naturais ou transformadas pelo homem, e de outro, de normas de uso, jurídicas ou definidas pelo costume, formais ou informais (SANTOS, 1996). Em obra anterior, Santos (2002, p. 237-238) já afirmava sobre que o conceito de formação socioespacial expressa uma totalidade, envolvendo as "especificidades de cada sociedade tomada como uma realidade historicamente determinada, fundada sobre uma base territorial, e essa realidade total pode ser vista na escala da região", pois é, ao mesmo tempo, uma estrutura subordinada e autônoma. Além disso, a formação socioespacial adquire certa feição de homogeneidade regional, pois envolve um tipo de organização espacial e de formas de relação entre cidade e campo.
Esse conceito permite-nos, portanto, transitar pelas diferentes escalas da territorialização do desenvolvimento (Tabela 3), desde o global, dos grandes grupos empresariais e organizações internacionais, até o local dos sistemas de produção de pequenos e médios empreendimentos e dos pactos e acordos de governança entre atores públicos e privados, passando pelo nível nacional, do Estado-nação, do mercado doméstico e dos capitais nacionais e estrangeiros, ao nível regional, de autoridades de governo e das políticas redistributivas do nível nacional. Eis a totalidade do desenvolvimento em seu entendimento territorial.

E o fato é que essas escalas, como instrumentos de apreensão da realidade investigada (CASTRO, 2006) estão em constante relação de superposição, sobreposição e conflito, pois toda ação global vai se territorializar em determinados locais de uma nação e de um contexto regional, e toda ação local está conectada, direta ou indiretamente, ao quadro econômico e regulatório regional e nacional, e estes se inserem no sistema internacional e na economia-mundo globalizados.

Tabela 3 - Escalas de análise da territorialização do desenvolvimento

\begin{tabular}{|c|c|}
\hline $\begin{array}{c}\text { Escalas espaciais } \\
\text { de análise }\end{array}$ & Territorialização do desenvolvimento \\
\hline Global & $\begin{array}{l}\text { Âmbito mais amplo de operação das grandes empresas e grupos transnacionais, das re- } \\
\text { des de financiamento internacional, das cadeias produtivas globalizadas, dos acordos e } \\
\text { instituições supranacionais, dos blocos regionais. É um quadro de regulação frágil, que } \\
\text { depende das ações dos Estados-nação em convenções internacionais. }\end{array}$ \\
\hline Nacional & $\begin{array}{l}\text { Lócus de ação dos Estados nacionais e do capital doméstico e estrangeiro. Abarca o con- } \\
\text { junto das unidades subnacionais e é reconhecido pelo conjunto de sua infraestrutura de } \\
\text { articulação, as atividades humanas e econômicas, as políticas de Estado, o conflito entre } \\
\text { capitais estrangeiros e o pequeno e grande capital nacional, das disparidades de renda } \\
\text { e investimentos entre regiões. É o quadro regulatório mais coeso e denso, mesmo diante } \\
\text { das políticas de desregulamentação e descentralização neoliberais dos anos } 1990 .\end{array}$ \\
\hline Regional & $\begin{array}{l}\text { É formado pelo conjunto de localidades em redes e apresenta uma coerência interna } \\
\text { definida por seus polos econômicos. É, ao mesmo tempo, resultado das estratégias de } \\
\text { desconcentração produtiva dos Estados e podem aparecer como entidades autônomas } \\
\text { com capacidade de estimular o desenvolvimento, promovendo mudanças estruturais. } \\
\text { Sua capacidade de regulação é mediana, pois é subordinada às políticas macro do Es- } \\
\text { tado e ações do capital global, mas pode ser fortalecida caso controlem determinadas } \\
\text { cadeias de valor e, em alguns países, possuam capacidade de planejamento e política } \\
\text { por meio da descentralização político-administrativa. }\end{array}$ \\
\hline Local & $\begin{array}{l}\text { Escala menor, pensada em termos de endogeneização das estratégias de desenvolvi- } \\
\text { mento a partir de pactos inéditos entre o público e o privado. Pode ser associada também } \\
\text { com o âmbito das municipalidades, as administrações locais e dos sistemas produtivos } \\
\text { articulados a determinados segmentos de atividade e concentrados localmente. Sua ca- } \\
\text { pacidade regulatória é frágil e de difícil mensuração, pois depende do protagonismo } \\
\text { de elites locais articuladas aos governos na busca de resolução de problemas sociais, } \\
\text { econômicos e políticos, sendo dependente das ações de outros níveis. }\end{array}$ \\
\hline
\end{tabular}

Fonte: Elaborada pelo autor 
Como exercício de generalização e de periodização, no esforço de escolher variáveis e colocá-las em um sistema de eventos (SANTOS; SILVEIRA, 2010), caracterizamos quatro grandes ciclos de territorialização do desenvolvimento no Brasil, composto por elementos gerais dos âmbitos nacional e regional. Assim, compreendemos a relevância da variável tempo no entendimento dos movimentos de territorialização e desterritorialização de aglomerados produtivos, tempo que acelera o ritmo de transformações na atualidade diante dos vetores tecnológicos, dos meios informacionais e da constante interligação entre partes territoriais através das redes de transportes e computacionais. Em contrapartida, o tempo aplicado ao espaço geográfico informa sobre as heranças do passado, através de formas e funções cristalizadas em usos do território, que influenciam os rumos dos projetos atuais de desenvolvimento, tanto como facilitadores (Ex.: economias externas e de aglomerações, fluidez territorial) quanto como entraves (Ex.: distâncias geográficas, estruturas obsoletas, deseconomias de aglomeração).

A ideia de sucessão de eventos, descontínua e assincrônica, marca os ciclos de desenvolvimento no Brasil e atua como um quadro de entendimento histórico-espacial para qualquer ação ou processo atual de desenvolvimento em diferentes escalas espaciais de apreensão.

Tabela 4 - Ciclos históricos de análise da territorialização do desenvolvimento no Brasil

\begin{tabular}{|c|c|}
\hline Ciclos temporais de análise & Territorialização do desenvolvimento \\
\hline $\begin{array}{c}\text { Industrialização } \\
\text { semi-artesanal } \\
\text { (De } 1910 \text { a 1930) }\end{array}$ & $\begin{array}{l}\text { Presença escassa de pequenas fábricas nas cidades, com utilização de técnicas } \\
\text { rudimentares e dependentes do saber-fazer local. Atendiam ao mercado local } \\
\text { e regional. A indústria ainda não controla totalmente a cadeia de produção } \\
\text { agrícola. O mercado de trabalho é ainda fragmentado, apresentando pequena } \\
\text { formalização e frágil participação sindical. }\end{array}$ \\
\hline $\begin{array}{c}\text { Industrialização fordista } \\
\text { periférica } \\
\text { (De } 1940 \text { - 1960) }\end{array}$ & $\begin{array}{l}\text { Atração de empresas multinacionais com tecnologias padronizadas e fortaleci- } \\
\text { mentos das empresas estatais. Concentração econômica no Sudeste. Políticas } \\
\text { de regionalização do desenvolvimento pontuais. Sedimentação do mercado de } \\
\text { emprego nas áreas urbanas e expansão da ação sindical, contemplando a con- } \\
\text { trapartida da segregação socioespacial via segmentação do mercado consumi- } \\
\text { dor e êxodo rural. Modelo de industrialização por substituições de importações. } \\
\text { Industrialização do campo através da "revolução verde". }\end{array}$ \\
\hline $\begin{array}{c}\text { Apogeu do fordismo e } \\
\text { transição para o modelo } \\
\text { toyotista } \\
(\text { Anos } 1970 \text { e 1980) }\end{array}$ & $\begin{array}{l}\text { Integração do mercado consumidor e elevação do grau de investimentos es- } \\
\text { trangeiros diretos. Constituição de um parque industrial completo e depend- } \\
\text { ente em São Paulo e início da desconcentração industrial devido às desecono- } \\
\text { mias de aglomerações e incentivos fiscais estatais. Manutenção de políticas de } \\
\text { planejamento regional outorgadas. Emergência de especializações produtivas } \\
\text { regionais em consonância à desconcentração econômica e mercados ainda in- } \\
\text { explorados. Consolidação das centrais sindicais e acirramento da luta entre } \\
\text { trabalhadores e empresários em São Paulo. Expansão da agricultura comercial } \\
\text { pelo Centro-oeste e integração em sistema agroindustrial. }\end{array}$ \\
\hline $\begin{array}{c}\text { Globalização e acumulação } \\
\text { flexível } \\
\text { (Anos 1990, 2000, 2010) }\end{array}$ & $\begin{array}{l}\text { Estagnação econômica e crise do Estado, com adesão às políticas liberais de } \\
\text { abertura comercial, inserção do capital financeiro, privatização de empresas } \\
\text { e serviços e desregulamentação parcial, além de um início de descentraliza- } \\
\text { ção administrativa. Oscilação no movimento de expansão do investimento do } \\
\text { capital transnacional, operando na forma de empresa em rede. Reforço da es- } \\
\text { pecialização produtiva dos lugares e surgimento de aglomerados de pequenas } \\
\text { e médias empresas em diversas regiões. Enfraquecimento sindical devido à } \\
\text { flexibilização do trabalho e prática de terceirização, com retração do emprego } \\
\text { industrial. Continuação do processo de desconcentração industrial inter-re- } \\
\text { gional. Hegemonia da agricultura científica globalizada em cinturões moder- } \\
\text { nos em tecnologias e informações. Expansão econômica dos serviços e reforço } \\
\text { do controle das metrópoles nacionais e regionais e aumento do número de } \\
\text { cidades de porte médio. }\end{array}$ \\
\hline
\end{tabular}

Fonte: Elaborado pelo autor 


\section{Considerações Finais}

O presente texto apresentou um esforço de construção de um modelo teórico e metodológico para estudos dos elementos de territorialização e desterritorialização do desenvolvimento em perspectiva escalar. Dividida em dois cenários, a análise contempla um referencial qualitativo baseado em quadros e tipologias para estudos regionais e locais sobre projetos e estratégias de desenvolvimento econômico e social. Assim, compreendemos que o desenvolvimento local, regional e nacional envolve, de forma intrínseca, a dicotomia da desterritorialização e reterritorialização no movimento constante de mobilidade organizada ou caótica do capital e do trabalho. Entende-se também que as redes de empresas aglomeradas ou dispersas configuram a base sobre a qual se dá a interligação entre ações de saída ou de chegada de determinados atores sociais em territórios específicos.

O primeiro nível, analítico, foi construído pensando-se no movimento de Territorialização-Desterritorialização-Reterritorialização, já amplamente discutido por Haesbaert (2004, 2006) e Saquet (2007), aplicando esse referencial dialético para entendimento dos aspectos territoriais de modelos de desenvolvimento sugeridos por Lipietz e Leborgne (1988) e por Benko (1996). Entendemos que todo aglomerado produtivo possui estratégias e opções para ampliar sua territorialização, como parte de cadeias produtivas territorializadas ou cadeias produtivas internamente localizadas, ou aderir à lógica da desterritorialização e reterritorialização multilocacional.

O segundo nível, conceitual, buscou aprimorar o quadro teórico ao sistematizar as características principais do desenvolvimento territorial, ou a territorialização do desenvolvimento, apresentando seus principais eixos qualitativos de análise (econômico, político, cultural, social, ambiental), suas escalas espaciais de compreensão (global, nacional, regional e local) e os ciclos de tempo generalizáveis para o caso brasileiro. Assim, pensou-se na polissemia do conceito de desenvolvimento em perspectiva territorial e na multidimensionalidade para seu estudo, em projetos e arranjos produtivo-espaciais regionais e locais.

Essa análise se encerra com a afirmação de que a construção de um quadro explicativo da territorialização do desenvolvimento é sempre um projeto inacabado à espera da atualização que o cenário contextual nos traz e que nos cobra uma revisão dos elementos analíticos e conceituais para adequação do tratamento da realidade empírica com a complexidade que ela demanda.

Assim, terminamos esse estudo tomando emprestadas as ideias de Saquet (2007, p. 172), que explicitam de forma clara nosso esforço em sintetizar processos territoriais tão amplos, imbricados e heterogêneos:

As dimensões sociais do território (economia, política e cultura) estão no mesmo nível. Porém, ora uma ou outra dimensão, em cada lugar ou período histórico, pode predominar diante das demais. O que muda e/ou permanece, para cada período, momento e lugar, é o arranjo territorial, através das formas espaciais e relações que esse arranjo assume. As territorialidades e temporalidades estão sempre aí, presentes, como matéria e ideia em unidade. A separação entre os fatores, elementos e relações pode ser um recurso didático no processo de conhecimento da vida.

\section{Referências}

BENKO, Georges. Economia, espaço e globalização: na aurora do século XXI. São Paulo: Hucitec, 1996.

BOISIER, Sérgio. Desarollo (local): De que estamos hablando? In: BECKER, Dinizar; BANDEIRA, Pedro S. F., Desenvolvimento local/regional: determinantes e desafios contemporâneos. Santa Cruz do Sul: Unisc, 2000. p. 151-185.

CASTELLS, Manuel. A sociedade em rede. São Paulo: Paz e Terra, 2003.

CASTRO, Iná E. O problema da escala. In: CASTRO, Iná E. et al. Geografia: conceitos e temas. Rio de Janeiro: Bertrand Brasil, 2006.

DALLABRIDA, Valdir R.; SIEDENBERG, Dieter; FERNANDEZ, Víctor R. Desenvolvimento a partir da perspectiva territorial. Desenvolvimento em questão, Unijuí, ano 2, n. 4, jul./dez. 2004.

DIAS, Leila C. Redes: Emergência e organização. In: CASTRO, Iná E. et al. Geografia: conceitos e temas. Rio de Janeiro: Bertrand Brasil, 2006.

FURTADO, Celso. Raízes do subdesenvolvimento. Rio de Janeiro: Civilização Brasileira, 2003.

HAESBAERT, Rogério. O mito da desterritorialização: Do "fim dos territórios" à multiterritorialidade. Rio de Janeiro: Bertrand Brasil, 2004.

A desterritorialização: Entre as redes e os aglomerados de exclusão. In: CASTRO, I. E. et al. Geografia: conceitos e temas. Rio de Janeiro: Bertrand Brasil, 2006. p. $165-206$. 
Des-reterritorialização e identidade: a rede "gaúcha" no Nordeste. Niterói: EDUF, 1997.

HAESBAERT, Rogério; PORTO-GONÇALVES, Carlos W. A nova desordem mundial. São Paulo: Edunesp, 2006.

HAESBAERT, Rogério; LIMONAD, E. O território em tempos de globalização. GeoUERJ, Rio de Janeiro, UERJ, v. 3, n. 5, p. 7-20, 1999.

HARVEY, David. Condição pós-moderna. 18. ed. São Paulo: Edições Loyola, 2009.

LIPIETZ, Alain; LEBORGNE, Danièle. O pós-fordismo e seu espaço. Espaço e debates, São Paulo, n. 25, p. 12-29, 1988.

PECQUEUR, B. A guinada territorial da economia global. Política e sociedade, Florianópolis, n. 14, abr. 2009.

PIRES, Elson Luciano S. As lógicas territoriais do desenvolvimento: diversidades e regulação. Interações, Campo Grande, v. 8, n. 2, set. de 2007.

RANDOLPH, Rainer. Sociedade em rede: Paraíso ou pesadelo? Reflexões acerca de novas formas dearticulação social e territorial das sociedades. GeoUERJ, ano
1, n.2, p. 27-53, 1999.

RANDOLPH, Rainer. Novas redes e novas territorialidades. III Simpósio Nacional de Geografia Urbana (Sinpurb). Rio de Janeiro: AGB/UFRJ/IBGE/CNPq, 1993.

SANTOS, Milton. A natureza do espaço: técnica e tempo, razão e emoção. São Paulo: Hucitec, 1996.

Por uma outra globalização: do pensamento único à consciência universal. São Paulo/Rio de Janeiro: Record, 2001.

Por uma Geografia nova: da crítica da Geografia a uma Geografia crítica. 6. ed. São Paulo: Edusp, 2002.

SANTOS, Milton; SILVEIRA, Maria Laura. O Brasil: território e sociedade no início do século XXI. 10. ed. São Paulo/Rio de Janeiro: Record, 2010.

SAQUET, Marcos A. Abordagens e concepções de território. São Paulo: Expressão Popular, 2007.

SPÓSITO, Eliseu S. Geografia e Filosofia: Contribuições para o ensino do pensamento geográfico. São Paulo: Edunesp, 2004. 